\title{
Intracardiac pressures in the human fetus
}

\author{
P Johnson, D J Maxwell, M J Tynan, L D Allan
}

\begin{abstract}
Objective-To obtain normal values for intracardiac pressures in the human fetus.

Design-Intracardiac pressures were measured directly in the four chambers of the human fetal heart during clinically indicated invasive obstetric procedures.

Setting-Department of fetal medicine in a tertiary referral centre.

Patients-39 fetuses between 16 and 29 weeks of gestation.

Results-The ventricular waveforms obtained were similar to those found in postnatal life. There was an increase in ventricular systolic and end diastolic pressures with advancing gestation. There was no difference between left and right ventricular pressures. Atrial pressures were equal and remained constant in the gestational age range studied.

Conclusions-Fetal cardiovascular pressure measurements in the normal fetus assist in understanding the fetal circulation, and provide a basis for the assessment of cases of congenital heart disease that may be amenable to intrauterine treatment.

(Heart 2000;84:59-63)
\end{abstract}

Keywords: fetus; ventricular pressure; congenital heart disease

The structure of the human fetal heart, both normal and abnormal, can be defined from at least 18 weeks of gestation. ${ }^{12}$ Using Doppler techniques, some aspects of fetal haemodynamics can also be investigated, including flow profiles, flow velocities, cardiac output, and the changes that occur in these variables with advancing gestation or in pathological states. ${ }^{3-8}$ Comparison of normal Doppler flow profiles with those obtained in pathological states may suggest an increase in pressure gradients between the cardiac connections, but absolute pressure within the heart cannot usually be predicted. The only circumstances where ventricular pressures can be estimated in utero are in those cases where there is mitral or tricuspid regurgitation, in which the gradient of the regurgitant jet will give an approximate estimate of left or right ventricular pressure, respectively. However, in the absence of pathology, mitral and tricuspid regurgitation are rare in fetal life. In addition, the normal end diastolic pressure within the fetal ventricles - an indication of myocardial compliance-is not known and can only be indirectly inferred from the mitral and tricuspid Doppler flow profiles. Intra-atrial and intraventricular pressures are important in understanding both normal and abnormal fetal heart function. In order to document normal values for intracavitary pressures during fetal life, the pressure within the four chambers of the fetal heart was measured during clinically indicated invasive obstetric procedures.

\section{Methods}

All procedures were performed in the fetal medicine unit at Guy's Hospital, London, and the study was approved by the institution's ethics committee. Patients were recruited from those women undergoing clinically indicated invasive procedures in the fetal medicine unit. These included diagnostic fetal blood sampling and mid-trimester termination of pregnancy. Following detailed explanation of the procedure used to obtain pressure measurements, all the patients gave informed consent. They were advised that the measurement of pressure would slightly increase the time taken to perform the clinical procedure. Indications for fetal blood sampling included rapid karyotyping in cases of structural fetal abnormality and in the investigation of genetic disease. We only studied cases where the umbilical cord was inaccessible for fetal blood sampling and the fetal ventricle was the only alternative. Midtrimester termination of pregnancy was performed for fetal abnormality or when the mental health of the mother was at risk, in accordance with the Abortion Act 1967 which permitted termination of pregnancy before 28 weeks' gestation and was in force at the time of the study.

Intracardiac pressures were measured in 39 fetuses with structurally normal hearts. Measurements were obtained during termination of pregnancy in 37 cases, and during diagnostic fetal blood sampling in the other two. An attempt was made to enter more than one cardiac chamber in cases undergoing termination of pregnancy. Attempts at cardiac puncture were made in a further 17 cases of termination, but either the procedure was technically unsuccessful owing to early gestation (less than 20 weeks) or the waveforms obtained were inadequate. These cases were excluded from the analysis.

\section{TECHNIQUES}

All patients had a detailed fetal anomaly scan performed, using a 3.5 or $5 \mathrm{MHz}$ curved array transducer on an Acuson 128 (Acuson, Mountain View, California, USA) or an Aloka 620 (Aloka Co, Tokyo, Japan). If a structural cardiac defect could not be excluded, targeted fetal echocardiography was performed in the 

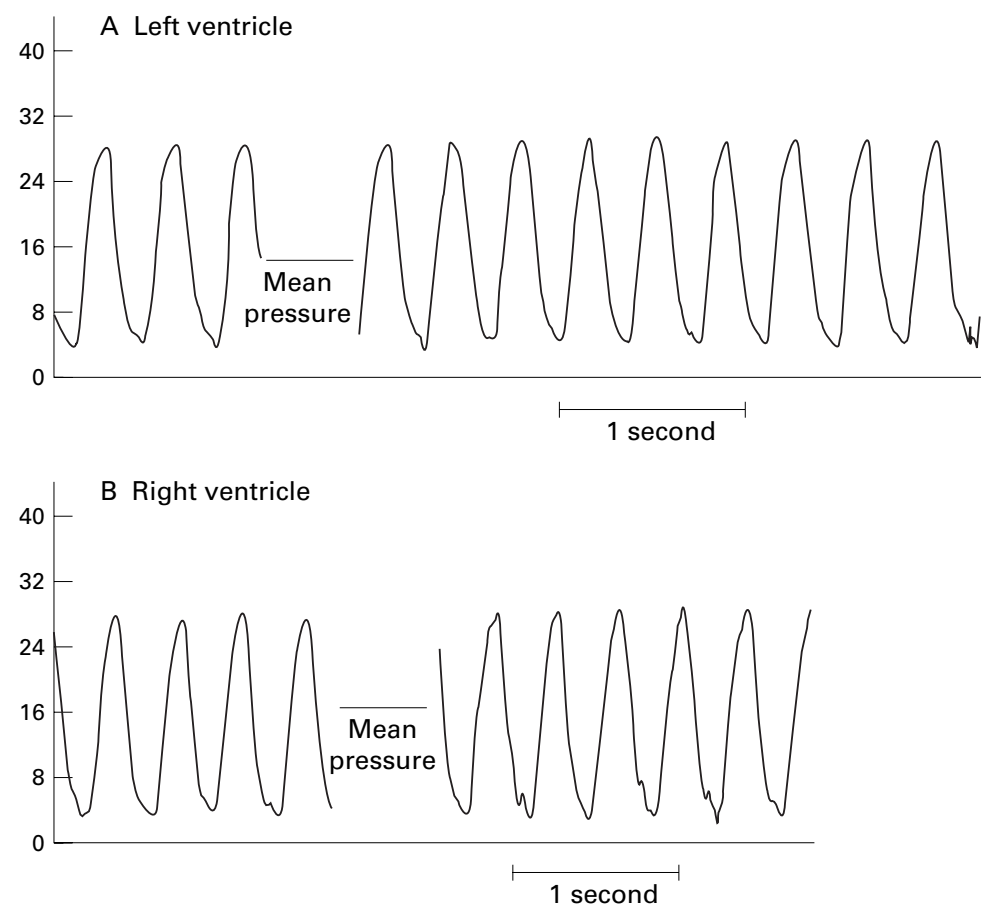

Figure 1 Pressure waveform of $(A)$ left and $(B)$ right ventricle in a normal fetal heart at 22 weeks' gestation

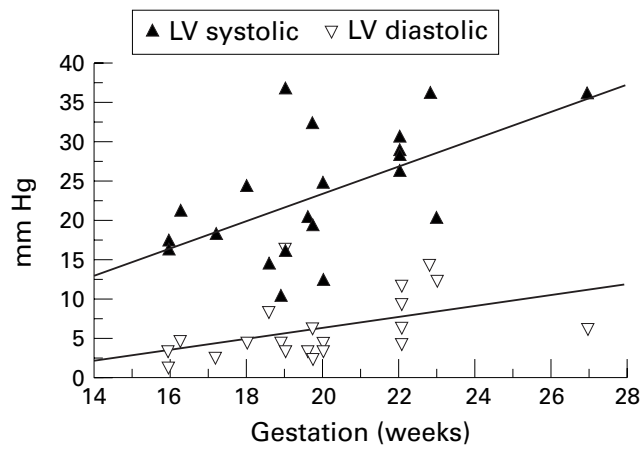

Figure 2 Plot of left ventricular pressure showing regression lines (coefficient 1.7416 (systolic), 0.7018 (diastolic)). LV, left ventricle.

\section{EQUIPMENT}

Pressures were measured using a fluid filled system connected to a solid state transducer and recording device, as this was the only system available at the time of the study. A standard $100 \mathrm{~cm}$ manometer tube filled with sterile heparinised saline ( $1 \mathrm{unit} / \mathrm{ml}$ ) was connected at one end to the hub of the needle sited in the fetal heart. The other end was connected by a three way tap to one aperture of a disposable plastic pressure dome. The other aperture of the dome was connected by a second three way tap to a syringe filled with heparinised saline and the dome was screwed onto the pressure transducer with an interface of water. The pressure transducer was connected to a Mingograf recording device, which was calibrated before each investigation. system (Hewlett Packard, Uxbridge, Middlesex, UK).

Estimation of gestational age was based on the first day of the last menstrual period unless there was a discrepancy between this and ultrasound assessment of greater than seven days. Ultrasound assessment included measurement of biparietal diameter, head circumference, abdominal circumference, and femur length. Where there was a discrepancy, the ultrasound assessment was used, unless earlier ultrasound had confirmed menstrual dates. The gestational age of the fetuses studied ranged between 16-29 weeks (mean 20.2 weeks).

All procedures were performed under aseptic conditions and continuous ultrasound guidance. Following cleansing of the skin and instillation of local anaesthetic, a 22 gauge single use spinal needle was inserted directly into the fetal heart, the line of approach and therefore the chambers entered being dependent on fetal position. Once the needle was in place, the stillette was removed and any diagnostic samples aspirated before measurement of intracardiac pressure. Following the measurement of intracardiac pressure, the needle was withdrawn into the amniotic cavity and the intra-amniotic pressure measured. In cases of termination of pregnancy, $10 \mathrm{mg}$ prostaglandin E2 (Upjohn, Crawley, West Sussex, UK) were instilled before the needle was finally withdrawn. If the mother's blood group was Rhesus negative, $500 \mathrm{IU}$ anti-D were given by intramuscular injection to prevent Rhesus immunisation.
CALCULATION OF PRESSURES

Pulsatile waveforms were obtained from each chamber of the heart, and recordings were accepted as satisfactory when a clear and reproducible waveform was obtained. All intracardiac pressures were zeroed to amniotic pressure-that is, amniotic pressure was subtracted from the intracardiac pressure. Mean systolic and diastolic pressures in the ventricles were calculated from 10 waveforms, with systolic pressure representing the highest point and end diastolic pressure being measured at the start of the rapid upsweep of the waveform.

\section{Results}

VENTRICULAR PRESSURE

Ventricular pressures were measured in 33 fetuses. Left ventricular pressure was measured in 21 cases and right ventricular pressure in 19. It was possible to measure both left and right ventricular pressures sequentially in seven fetuses undergoing termination of pregnancy. The pressure waveform obtained from left and right ventricles was similar in shape to that obtained in postnatal life (fig 1). Both systolic and end diastolic pressures in the left and right ventricles increased with advancing gestation (figs 2 and 3).

In the left ventricle, there was a small atrial component and a rapid increase in pressure during systole, followed by a rapid fall during ventricular diastole. The systolic and diastolic pressures increased significantly in a linear fashion with gestational age. The regression 


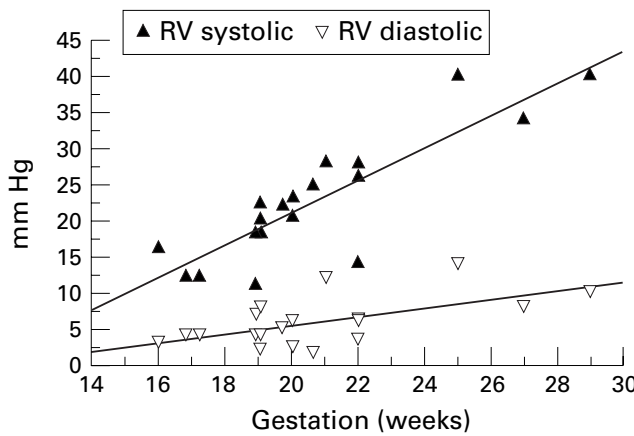

Figure 3 Plot of right ventricular pressure showing regression lines (coefficient 2.2410 (systolic), 0.6037 (diastolic)). $R V$, right ventricle.

Table 1 Comparison of left and right ventricular pressures in the same fetus

\begin{tabular}{lll}
\hline $\begin{array}{l}\text { Patient number } \\
\text { (weeks gestation) }\end{array}$ & $\begin{array}{l}\text { Left ventricle } \\
(\mathrm{mm} \mathrm{Hg})\end{array}$ & $\begin{array}{l}\text { Right ventricle } \\
(\mathrm{mm} \mathrm{Hg})\end{array}$ \\
\hline $1(27)$ & $36 / 6$ & $34 / 8$ \\
$2(16)$ & $16 / 3$ & $16 / 3$ \\
$3(22)$ & $28.6 / 3.8$ & $27.8 / 3.4$ \\
$4(20)$ & $12 / 4$ & $20.5 / 2.4$ \\
$5(19)$ & $19 / 6$ & $22 / 5$ \\
$6(22)$ & $26 / 6$ & $26 / 6$ \\
$7(19)$ & $10 / 4$ & $11 / 4$ \\
\hline
\end{tabular}

coefficient for the systolic pressure was 1.7416 $(p=0.006)$, and for the diastolic pressure, 0.7018 ( $p=0.042$ ) (fig 2).

The waveform from the right ventricle was similar to that obtained from the left, with a linear increase in systolic and diastolic with gestation. The coefficient for right ventricular systolic pressure was $2.2410(\mathrm{p}=0.000)$ and for diastolic pressure, 0.6037 ( $\mathrm{p}=0.007$ ) (fig 3 ).

In seven fetuses with normal hearts, pressures were recorded in both left and right ventricles. The data from these fetuses are provided in table 1 . There was no significant difference between the left and right pressures using a paired $t$ test $(t=-1.386 \quad(95 \%$ confidence interval (CI) -4.621 to 1.850$)$ for systolic; $t=0.1429$ (95\% CI -0.896 to 1.182 ) for diastolic).

\section{ATRIAL PRESSURES}

Atrial pressure was measured in 19 fetuses, with measurements from the left atrium in 13 and from the right in six. It was not possible to measure both left and right atrial pressure in any case. Waveforms obtained from the atria were similar to that seen in postnatal life, although they were very difficult to obtain without damping. They were triphasic in form (data not shown). However, it was not possible to distinguish the "a" wave from the "v" wave without a simultaneous ECG. In view of the poor quality of most waveforms, only mean pressures were analysed. In the left atrium, the mean pressure was $3.357 \mathrm{~mm} \mathrm{Hg}$ and in the right, $3.660 \mathrm{~mm} \mathrm{Hg}$. There was no significant change with gestation ( $p=0.209$ left, and $\mathrm{p}=0.631$ right).

\section{Discussion}

When fetal blood sampling is clinically indicated, our preferred site for positioning the needle is at the placental insertion of the umbilical cord. Alternatives are the fetal insertion of the cord, the intrahepatic vein, a free loop of cord, and the fetal heart. In our experience, there is no increased risk of pregnancy loss whichever route is chosen. ${ }^{9}$ However, the fetal heart was only entered if other sites were inaccessible because of fetal lie and visualisation. Thus in two instances of diagnostic fetal blood sampling the fetal heart was entered directly with a needle that could also be used to measure ventricular pressure. A diagnostic sample of between 1-3 $\mathrm{ml}$ of fetal blood was obtained before pressure measurement. While it is acknowledged that the aspiration of even such a small volume of blood might alter the haemodynamics, it was felt unethical to perform pressure measurements before the required sample was obtained, in case the needle became dislodged and it was not subsequently possible to obtain the necessary sample. However, in pregnancies undergoing termination $(n=37)$, no blood was aspirated other than to confirm that the needle was correctly sited (approximately $0.1 \mathrm{ml}$ ). As the diagnostic procedures were performed in the late second trimester and in the third trimester, when the fetoplacental volume is in excess of $100 \mathrm{ml},{ }^{10}$ it is unlikely that aspiration of less than $5 \%$ of the circulating volume would have an effect on cardiac pressures.

The reliability of a pressure measuring system is dependent on the frequency response, which is affected by the elasticity of the walls and the bore of any tubing used within the system. The use of a fine needle and $100 \mathrm{~cm}$ of manometer tubing adversely affects the frequency response, which must be measured in order to validate the system. In this case, frequency response was measured by the generation of a square wave fall in pressure (the "pop" test). ${ }^{11}$ In a series of more than 20 measurements, the frequency response of the system was calculated to be $7.94 \mathrm{~Hz}$.

Cardiovascular pressure waveforms are complex when analysed by Fourier analysis, and there may be significant contributions up to the 10th harmonic. For accurate measurement of pulsatile pressures such as $\mathrm{dP}$ and $\mathrm{dT}$, it is necessary to have a system with a flat frequency response up to $20 \mathrm{~Hz}$. However, for analysis of absolute pressure values rather than changes with time, reliable results can be obtained with a lower frequency response, provided it is at least that of the frequency of the signal. As fetal cardiac pressures are biphasic, a frequency response of at least $4 \mathrm{~Hz}$ is required. Thus the system used conformed with this requirement.

In this paper we provide the first data on human fetal cardiac pressures measured directly. The data obtained are consistent with those obtained in the fetal animal model, where pressures in the two ventricles are similar ${ }^{12}$ and the arterial pressure ranges between 35-65 mm Hg. ${ }^{13-18}$ However, the values in the lamb were obtained in fetuses of between 120 days and term (term in the fetal sheep is 150 days), which corresponds to a much later gestational age than the human fetuses we studied. Our data are also consistent with arterial pressure obtained in premature infants, 

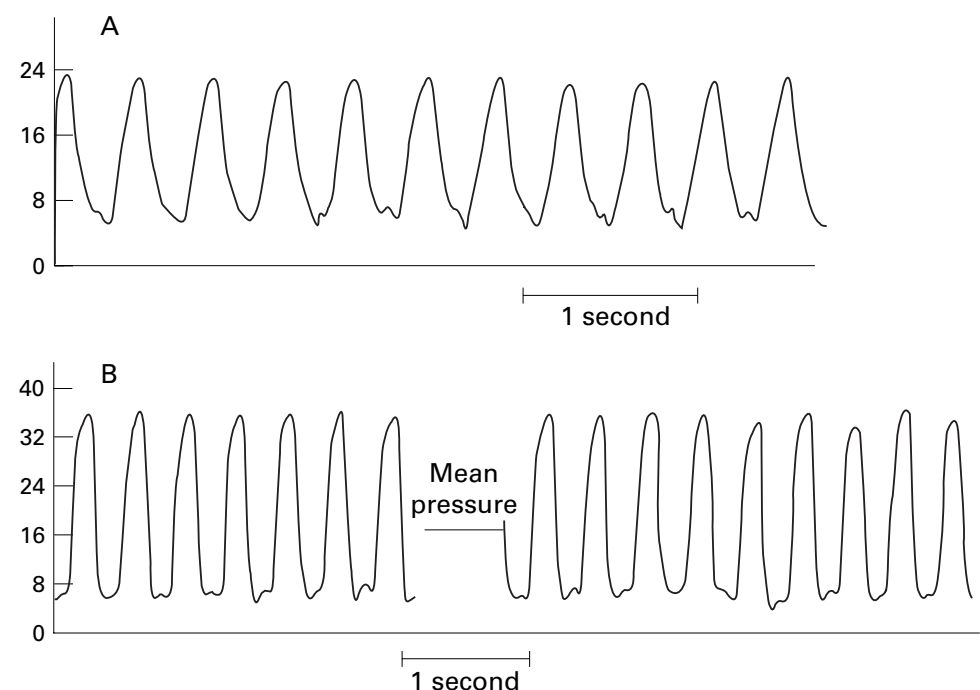

Figure 4 Left ventricular pressure waveforms at (A) 16 weeks and (B) 27 weeks showing the change in appearance of atrial contraction.

which ranges from $35-70 \mathrm{~mm} \mathrm{Hg}$ between 26 and 37 weeks. ${ }^{19} 20$ In the ventricles of the normal heart, we found changes in waveform and pressure with advancing gestation. An increase in systolic pressure and pulse pressure probably reflects both changes in the perfusion requirements of the increasing body mass of the developing fetus and the increasing force of ventricular ejection. This is a result of the growth of the ventricular wall thickness and of the increasing maturation of the myocardium..$^{21}$ It is also probable that there is more variation in blood pressure with altered fetal state as gestation advances. It is likely that systolic pressures continue to increase in a linear fashion with gestation, although the oldest fetus in which pressure was measured in this study was 29 weeks. The measurement obtained in this fetus was in agreement with normal values for blood pressure in a premature infant of the same postconceptional age. The end diastolic pressure in the left ventricle in this study showed a range of between $1-14 \mathrm{~mm} \mathrm{Hg}$, which is also consistent with a range of $1-11 \mathrm{~mm} \mathrm{Hg}$ measured in the fetal lamb. ${ }^{18}$

There is a change in the pressure waveform in both left and right ventricles with advancing gestation. In early gestation, atrial contraction appears on the down sweep, corresponding to ventricular relaxation. As gestation increases, the atrial contraction occurs at the nadir of ventricular pressure, then becoming superimposed on the initial upsweep of ventricular contraction by 29 weeks (fig 4). The intervals of electrical activity from the ECG do not change. Thus the timing of atrial contraction does alter. However, the rate of change of pressure during ventricular systole becomes more rapid with advancing gestation. This further reflects changes in myocardial maturity, evidenced in vivo by changes in the speed of calcium movement. ${ }^{21}$

Whether or not the left and right ventricle generate equal pressures has long been of interest. In the data from this study, the slope of the linear increase is greater in the right than in the left ventricle. However, in those fetuses in which both left and right ventricular pressures were recorded, there was no significant difference between the two ventricles. The apparent difference in the rate of increase is likely to reflect the small numbers in the study, with the possibility of one outlying result affecting the statistical analysis. The pressure gradient between the ventricles may be variable over time. There is some evidence for this from cardiac Doppler studies of fetuses with isolated ventricular septal defects. The direction of the interventricular shunt was found to vary from fetus to fetus and within an individual fetus at differing times in gestation. ${ }^{22} 23$

Obtaining a good pressure tracing in the atria was more difficult than in the ventricles, perhaps because of the smallness of the cavities. The right atrial mean pressure was only slightly greater than the left. This is also found in the fetal lamb model, where the atrial pressures were not significantly different, at $3.5 \mathrm{~mm} \mathrm{Hg}$ and $3 \mathrm{~mm} \mathrm{Hg}$, respectively. ${ }^{13} \mathrm{~A}$ jet of blood from the ductus venosus pushes open the foramen ovale flap into the left atrium ${ }^{24}$ and permits blood from the ductus venosus to flow across the foramen ovale with minimal pressure differences between the left and right atria. ${ }^{14}{ }^{15}$ There does not appear to be an increase in atrial pressure with advancing gestation, which is in keeping with published data on fetal umbilical venous pressure. ${ }^{25} 26$ However, it is possible that atrial pressure increases in line with systemic and pulmonary venous return but that the detection of such an increase may lie beyond the sensitivity of the equipment used in this study.

These normal data provide a basis for the understanding and investigation in utero of cases of congenital heart disease with abnormal intracavitary pressures, such as aortic or pulmonary stenosis. ${ }^{27}$ Comparison of pressure measurements in such cases with the normal values may provide additional information on the severity of obstruction and on ventricular function, and aid in the selection of cases for prenatal treatment.

\section{CONCLUSIONS}

The data in this study confirm an increase in ventricular pressures with gestation. There was no difference between left and right ventricular pressures within the same fetus. Atrial pressure did not increase with gestation. The ventricular pressure waveforms show changes that correspond to changes in maturation of the myocardial contractility seen in animal studies. Measurement of intracardiac pressures in disease states may provide additional information on ventricular function.

This study was funded by the British Heart Foundation.

1 Allan LD, Tynan MJ, Campbell S, et al. Echocardiographic and anatomical correlates in the fetus. Br Heart $f$ $1980 ; 44: 444-51$

2 Allan LD, Crawford DC, Anderson RH, et al. Echocardiographic and anatomical correlations in fetal congenital heart disease. Br Heart $\mathcal{f}$ 1984;52:542-8.

3 Kenny JF, Plappert T, Doubilat P, et al. Changes in intracardiac blood flow velocities and right and left ventricular diac blood flow velocities and right and left ventricular stroke volumes with gestational age in the normal human fetus; a prospective Doppler

4 Allan LD, Chita SK, Al-Ghazali W, et al. Doppler echocardiographic evaluation of the normal human fetal heart. $B r$ diographic evaluation of
Heart $\mathcal{F} 1987 ; 57: 528-33$. 
5 Reed KL, Appleton CP, Anderson CF, et al. Doppler studies of vena cava flows in human fetuses. Circulation

6 Schmidt KG, Tommaso M, Silverman NH, et al. Doppler echocardiographic assessment of fetal descending aortic and umbilical blood flows. Validation studies in lambs. Cir culation $1991 ; 83: 1731-7$.

7 van der Mooren K, Barrendregt LG, Wladmiroff JW. Fetal atrioventricular and outflow tract flow velocity waveforms during normal second half of pregnancy. Am $\mathcal{F}$ Obstet Gynecol 1991;165:668-74.

8 Better DJ, Kaufman S, Allan LD. The normal pattern of pulmonary venous flow on pulsed Doppler examination of the human fetus. F Am Soc Echocardiogr 1996;9:281-5.

9 Maxwell D, Johnson P, Hurley P, et al. Fetal blood sampling and pregnancy loss in relation to indication. $\mathrm{Br} \mathcal{F}$ Obstet Gynaecol 1991;98:892-7.

10 Nicolaides KH, Clewell WH, Rodeck CH. Measurement of human fetoplacental blood volume in erythroblastosis fetalis. Am 7 Obstet Gynecol 1987;157:50-3.

11 Butler PRE, Oldershaw PJ. Measurement of pressure. In: Mendel D, Oldershaw PJ, eds. A practice of cardiac catheterisation. Oxford: Blackwell Scientific, 1986:164-89.

12 Thornburg K, Morton M. Filling and arterial pressures as determinants of RV stroke volume in the sheep fetus. Am F Physiol 1983;244:H656-63.

13 Reller M, Morton M, Reid D, et al. Fetal lamb ventricles respond differently to filling and arterial pressures and to in utero ventilation. Pediatr Res 1987;22:621-6.

14 Anderson D, Bissonnette J, Faber J, et al. Central shunt flows and pressures in the mature fetal lamb. Am f Physio 1981;241:H60-6.

15 Anderson D, Faber J, Morton M, et al. Flow through the foramen ovale of the fetal and new-born lamb. F Physiol (Lond) 1985;365:29-40

16 Itskovitz J, LaGamma E, Rudolph A. Baroreflex control of the circulation in chronically instrumented fetal lambs. Circ Res 1983;52:589-96.
17 Lawler F, Brace R. Fetal and maternal arterial pressures and heart rates: histograms, correlations, and rhythms. Am 7 Physiol 1982;243:R433-44.

18 Anderson P, Manring A, Glick K, et al. Biophysics of the developing heart. III. A comparison of the left ventricular dynamics of the fetal and neonatal lamb heart. Am f Obstet Gynecol 1982;143:195-203.

19 Tan K. Blood pressure in the very low birth weight infants in the first 70 days of life. F Pediatr 1988;112:266-70.

20 Nwanko M, Lorenz J, Gardiner J. A standard protocol for blood pressure measurement in the newborn. Pediatrics 1997;99:E10.

21 Fisher DJ, Tate CA, Phillips S. Developmental regulation of the sarcoplasmic reticulum calcium pump in the rabbit heart. Pediatr Res 1992;31:474-9.

22 Akita A, Harima N, Nawata S, et al. Two dimensional and Doppler echocardiographic evaluation of intrauterine blood flow dynamics in the fetuses with a ventricular septal defect. Acta Obstet Gynecol fpn 1991;43:1606-12.

23 Chao R, Ho E, Hseih K. Fluctuations of interventricular shunting in a fetus with isolated ventricular septal defect. Am Heart f 1994;127:955-8.

24 Kiserud T, Eik-Ness SH, Blaas HK, et al. Ultrasonographic velocimetry of the fetal ductus venosus. Lancet 1991;338: $1412-14$.

25 Castle B, Mackenzie IZ. In vivo observations on intravascular blood pressure in the fetus during mid-pregnancy. In: Rolfe P, ed. Fetal physiological measurements. London: Butterworth, 1986:65-9.

26 Weiner CP, Heilskov J, Pelzer G, et al. Normal values for human umbilical venous and amniotic pressures and their alteration by fetal disease. Am f Obstet Gynecol 1989;161: $714-17$

27 Maxwell D, Allan L, Tynan M. Balloon dilatation of the aortic valve in the fetus: a report of two cases. Br Heart 7 1991;65:256-8.

\section{IMAGES IN CARDIOLOGY}

\section{Defective limb growth after retrograde balloon valvuloplasty}

This case involves an infant born prematurely at 24 weeks' gestation, with a birth weight of 560 g. After three weeks cardiac decompensation with pulmonary oedema and renal failure occurred. Severe coarctation of the aorta with a pressure gradient of $53 \mathrm{~mm} \mathrm{Hg}$ was diagnosed by echocardiography. Since surgery was not an option, balloon valvuloplasty was performed after cutdown of the right femoral artery using a 3 French sheath (diameter of the sheath $1.1 \mathrm{~mm}$; diameter of the femoral artery assessed by duplex sonography $0.7 \mathrm{~mm}$ ). Balloon dilatation was performed using coronary angioplasty catheters (balloon diameter $3 \mathrm{~mm}$ and $4 \mathrm{~mm}$ ). The pressure gradient was reduced to $12 \mathrm{~mm} \mathrm{Hg}$. At follow up echocardiography eight weeks after the procedure, there was no recurrence of the coarctation.

Complete thrombotic occlusion of the right femoral artery was evident early after the intervention, despite intravenous administration of heparin. Fibrinolysis was considered to be associated with an unacceptably high risk in this prematurely born infant. Although rapid collateral formation in the groin led to restoration of pedal pulses, defective limb growth

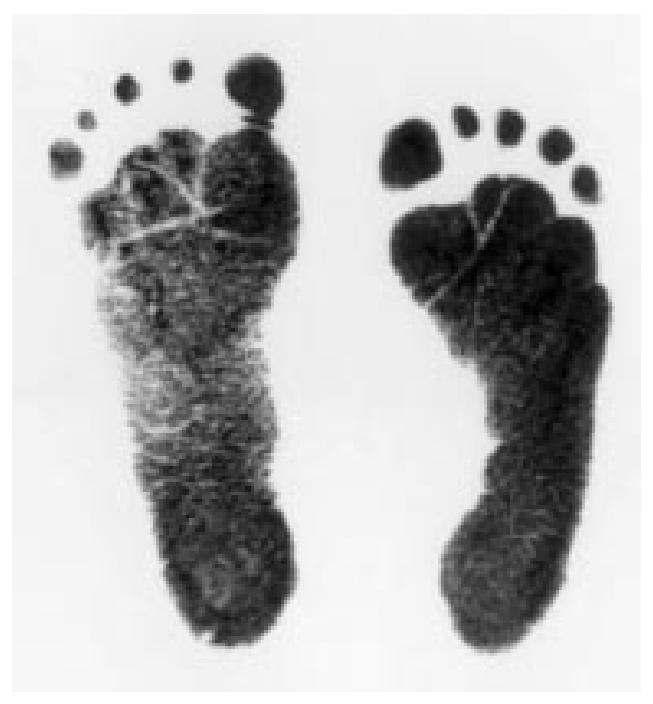

became evident eight weeks after the intervention (actual size).

MATTHIAS PEUSTER JOACHIM FREIHORST GERD HAUSDORF 